\title{
Associations of Psychosocial Factors With Heart Rate and Its Short-Term Variability: Multi-Ethnic Study of Atherosclerosis
}

\author{
Tetsuya Ohira, MD, PhD, Ana V. Diez Roux, MD, PhD, Ronald J. Prineas, MD, PhD, \\ Mohammad A. Kizilbash, MD, MSCi, Mercedes R. Carnethon, PhD, and Aaron R. Folsom, MD, MPH
}

\begin{abstract}
Objective: To examine the association of psychosocial factors with heart rate (HR) and its variability across multiple ethnic groups and by gender. Increased HR and reduced HR variability are markers of increased cardiovascular risk. Methods: Between 2000 and 2002, 6814 men and women (2624 Whites, 1895 African-Americans, 1492 Hispanics, and 803 Chinese) aged 45 to 84 years took part in the first examination of the Multi-Ethnic Study of Atherosclerosis. Associations of psychosocial variables with mean values of HR and its short-term variability were tested, using multivariate regression models. Results: In age, gender, race/ethnicity, and risk factor-adjusted analyses, a depressive symptom score was positively associated with HR and inversely associated with HR variability (standard deviation of normal-to-normal $(\mathrm{N}-\mathrm{N})$ interbeat intervals (SDNN) and the root mean square of successive differences in N-N intervals (RMSSD)). The adjusted mean differences per 1-SD (8 points) increment of depression score for HR, RMSSD, and SDNN were 0.5 (95\% confidence interval (CI), 0.2-0.7), -0.8 (95\% CI, -1.5 to -0.2 ), and -0.7 (95\% CI, -1.1 to -0.2 . The social support score was inversely associated with HR, but nonsignificantly associated with RMSSD and SDNN. There was no association of trait anger or trait anxiety with HR, RMSSD, or SDNN. Associations were generally consistent in men and women. Conclusions: These findings generally support the hypothesis that depression may be associated with increased HR and reduced HR variability, which increase the risk of cardiovascular diseases. Key words: autonomic nervous system, coronary artery disease, depression, heart rate, psychosocial factor, race/ethnicity.
\end{abstract}

$\mathbf{B M I}=$ body mass index; $\mathbf{B P}=$ blood pressure; $\mathbf{H R}=$ heart rate; CES-D = Center for Epidemiologic Studies Depression Scale; CHD = coronary heart disease; ECG = electrocardiogram; MESA = Multi-Ethnic Study of Atherosclerosis; MET = metabolic equivalent; RMSSD = root mean square of successive differences in normal-to-normal interbeat intervals; $\mathbf{S D N N}=$ standard deviation of normal-to-normal interbeat intervals.

\section{INTRODUCTION}

$P$ sychosocial factors, such as depression, perceived stress, anger, and social support, are associated with increased risk of cardiovascular morbidity and mortality (1-4), but the mechanisms for these associations are not established. Neurohormonal dysregulation, such as altered autonomic nervous system functioning, is one of several plausible explanations of how psychosocial factors may affect cardiovascular disease occurrence. Persons with depression, anxiety, and suppressed anger have been reported to have increased heart rate (HR) and reduced HR variability (5-9). Increased HR and/or reduced HR variability are associated with a higher incidence of coronary heart disease (CHD) $(10-12)$ and rapid progression of coronary artery disease (13).

From the Division of Epidemiology and Community Health (T.O., A.R.F.), University of Minnesota, Minneapolis, Minnesota; Department of Social and Environmental Medicine (T.O.), Osaka University, Osaka, Japan; Department of Epidemiology (A.V.D.R.), University of Michigan, Ann Arbor, Michigan; Division of Public Health Sciences (R.J.P.), Wake Forest University School of Medicine, Winston-Salem, North Carolina; and the Department of Preventive Medicine (M.A.K., M.R.C.), Feinberg School of Medicine, Northwestern University, Chicago, Illinois.

Address correspondence and reprint requests to Aaron R. Folsom, Division of Epidemiology and Community Health, School of Public Health, University of Minnesota, 1300 South 2nd Street, Suite 300, Minneapolis, MN 554541015. E-mail: folsom@epi.umn.edu

Received for publication February 1, 2007; revision received September 26, 2007.

MESA is supported by contracts N01-HC-95159 through N01-HC-95165 and N01-HC-95169 from the National Heart, Lung, and Blood Institute (all authors). Dr. Ohira was also supported by the Research Fellowship Program of the Uehara Memorial Foundation (Tokyo, Japan).

DOI: $10.1097 /$ PSY.0b013e318160686a
Most previous studies of the associations between psychosocial factors and HR and its variability have been performed in clinical settings $(6-8,14,15)$. For instance, a study conducted in 32 patients with major depression and 64 nondepressed control subjects reported that HR variability indices were significantly lower in patients with severe depressive symptoms than in the control group (8). However, because depressive symptoms within the normal range have been associated with increased incidence of cardiovascular diseases in general populations $(1,16)$, data are needed on the associations of depression with HR and its variability in populationbased samples. Further, because mean values of HR variability indices and psychosocial factors vary by gender and race $(17,18)$ and the vulnerability to psychosocial factors could also be modified by social or biologic circumstances linked to gender or race/ethnicity, it is important to examine whether the association of psychosocial factors with HR and its variability differ by gender and race or ethnicity. Only a few studies have been conducted among healthy subjects $(5,9)$, and no study has examined the associations of psychosocial factors with HR and its variability in various ethnic groups and by gender. Therefore, using data from the Multi-Ethnic Study of Atherosclerosis (MESA), we examined the associations of depression, social support, anger, and anxiety with HR and its variability in a large, population-based sample free of cardiovascular disease. We also investigated whether these associations differed by gender or race/ethnicity.

\section{METHODS}

\section{Study Population}

The MESA cohort includes 3213 men and 3601 women aged 45 to 84 years who were free from cardiovascular disease (specifically diagnosed CHD, stroke, and atrial fibrillation). Participants were recruited between 2000 and 2002 in six US field centers: Baltimore, Maryland; Chicago, Illinois; Forsyth County, North Carolina; Los Angeles County, California; New York, New York; and St. Paul, Minnesota. The study design is described in detail elsewhere (19).

We excluded participants with missing or poor quality electrocardiographic data $(n=94)$ or missing data for risk factors, such as blood pressure (BP), anthropometrics, and psychosocial variables $(n=68)$. The remaining 
6652 participants (2550 Whites, 1843 African-Americans, 1472 Hispanics, and 787 Chinese) were included in the analyses. The study protocol was approved by the Institutional Review Boards at each site and informed written consent was obtained from each participant.

\section{Baseline Measurements}

Questionnaires were administered as part of the baseline visit in English, Spanish, or Chinese to obtain information about anger and anxiety (the Spielberger trait anger and anxiety scales) (20), depression (the Center for Epidemiologic Studies Depression Scale, CES-D) (21), and social support (the Perceived Social Support Scale) (22). There were weak-to-moderate correlations among the psychosocial variables; the Spearman correlation coefficients were -0.38 between depression and social support, 0.30 between depression and anger, 0.61 between depression and anxiety, -0.18 between social support and anger, -0.33 between social support and anxiety, and 0.40 between anger and anxiety.

During the examination, height, weight, and waist and hip circumferences were measured. We measured the patient's resting BP three times, using an automated oscillometric sphygmomanometer (Model Pro 100, Dinamap, Critikon, Tampa, Florida), while the patient was in the seated position. The average of the last two measurements was used in analysis. Hypertension was defined as systolic BP of $\geq 140 \mathrm{~mm} \mathrm{Hg}$, diastolic BP of $\geq 90 \mathrm{~mm} \mathrm{Hg}$, and/or current treatment with antihypertensive medication. Body mass index (BMI) was calculated as weight $(\mathrm{kg}) /$ height $(\mathrm{m})^{2}$. Physical activity was measured by using a detailed, semiquantitative questionnaire adapted from the CrossCultural Activity Participation Study (23). Minutes per week of all light, moderate, and vigorous activities were multiplied by their individual metabolic equivalent (MET) values to compute the total MET min/wk.

After at least a 5-minute rest, three consecutive 10 seconds of simultaneous 12-lead electrocardiograms (ECGs) were obtained (Marquette MAC1200, GE Healthcare, Milwaukee, WI) and read electronically after transmission over analogue phone lines to a Central ECG Reading Center blinded to all clinical and personal details of the participants. ECG abnormalities were elicited by a program using Nova code criteria (24) and Minnesota code criteria (25). On ECGs with $>50 \%$ normal-to-normal $(\mathrm{N}-\mathrm{N})$ interbeat intervals, two ECG measures of HR variability were calculated using three consecutive 10-second recordings: the standard deviation of N-N intervals $(\mathrm{SDNN})$ and the root mean square of successive differences of $\mathrm{N}-\mathrm{N}$ intervals (RMSSD) (all in milliseconds). The calculation of these measures was verified by senior electrocardiographers and a biostatistician in a test data set of 264 ECGs. In this study, most $(92 \%)$ of the ECGs were assessed in the morning, and the ECG-derived measures, SDNN and RMSSD, reflected shorter-term, resting parasympathetic (respiratory) variation. These measures have, however, been related to long-term mortality and the development of CHD. The Spearman correlation coefficients were -0.32 between HR and SDNN, -0.44 between HR and RMSSD, and 0.92 between SDNN and RMSSD. In MESA, the repeatability of short-term HR variability indices is good, and the correlation coefficients (95\% confidence intervals) between 10 seconds and 6 minutes were $0.76(0.68-0.82)$ for SDNN and $0.82(0.75-$ $0.86)$ for RMSSD (26).

A blood sample was drawn from participants, and aliquots were prepared for central analysis and for storage at the University of Vermont and the University of Minnesota. Measurements were performed to allow several physiologic domains to be addressed, including lipids and lipoproteins, systemic inflammation, and glucose. We defined diabetes as fasting serum glucose of $\geq 7.0 \mathrm{mmol} / \mathrm{L}(\geq 126 \mathrm{mg} / \mathrm{dl})$ or pharmacological treatment for diabetes.

\section{Statistical Analysis}

Although the distributions of RMSSD and SDNN were right-skewed, our analyses used log-transformed variables and back-transformed geometric means. Analysis of covariance was used to examine the association of HR, RMSSD, and SDNN with cardiovascular risk factors. Linear regression analysis was used to test for associations of psychosocial variables with HR, RMSSD, and SDNN, and fit of models was tested using residual analysis. The adjusted standardized regression coefficients of HR, RMSSD, and SDNN per
$1 \mathrm{SD}$ increment of psychosocial variables were examined in age, gender, and race/ethnicity adjusted and multivariate adjusted models. Covariates included age (years), gender, race/ethnicity, systolic BP ( $\mathrm{mm} \mathrm{Hg}$ ), use of antihypertensive medication (yes, no), smoking status (never/former, current smokers), BMI $\left(\mathrm{kg} / \mathrm{m}^{2}\right)$, diabetes mellitus (yes, no), total cholesterol level ( $\left.\mathrm{mg} / \mathrm{dl}\right)$, and physical activities (MET min/wk). These variables were included because they may be confounders of the association between psychosocial variables and HR or its variability and were included as covariates in previous studies $(7,9)$. Participants taking $\beta$ blockers $(n=602)$ were deleted from analyses concerning associations of psychosocial factors with HR and its variability, because $\beta$ blockers could modify the associations. We also compared values of HR, RMSSD, and SDNN between apparently depressed and nondepressed participants using a cut-off score of 16 , which is generally used to distinguish depression using the CES-D $(21,27)$. All statistical analyses were conducted using SAS, version 8.1 (SAS Institute, Inc., Cary, North Carolina).

\section{RESULTS}

Age- and race/ethnicity-adjusted mean values of HR, RMSSD, and SDNN were higher among women than among men (Table 1). Compared with other ethnic groups, AfricanAmericans had higher age- and gender-adjusted mean values of RMSSD (all $p$ values were $<.001$ for African-Americans versus Whites, Hispanics, and Chinese) and SDNN (all $p$ values were $<.001$ for African-Americans versus Whites, Hispanics, and Chinese). Age was inversely associated with gender- and race/ethnicity-adjusted mean values of RMSSD ( $p$ for trend $<.001$ ) and SDNN ( $p$ for trend $<0.001$ ).

Age-, gender-, and race/ethnicity- adjusted mean values of HR were higher among participants with hypertension, high cholesterol levels ( $\geq 220 \mathrm{mg} / \mathrm{dl}$ ), diabetes mellitus, or obesity (BMI $\geq 30 \mathrm{~kg} / \mathrm{m}^{2}$ ) than among participants without each of these cardiovascular risk factors (Table 2). Participants with hypercholesterolemia, hypertension, or diabetes mellitus also had lower mean values of RMSSD and SDNN. There was no association of current smoking with HR, RMSSD, or SDNN. However, we observed a significant interaction between smoking and race/ethnicity for HR ( $p$ for interaction $=.03$ ), but no interaction for HR variability. In Whites, the age- and gender-adjusted mean value of HR was higher among current smokers than among nonsmokers; the adjusted HR was 64.3 for current smokers and 62.8 for nonsmokers $(p=.009)$, whereas there was no significant association between smoking and HR in other ethnic groups.

Table 3 presents associations of psychosocial variables with HR and its variability. The depression score was significantly positively associated with HR, and inversely associated with RMSSD and SDNN after adjustment for age, gender, and race/ethnicity. The adjusted standardized regression coefficients (adjusted mean differences per 1-SD increment of depression score) for HR, RMSSD, and SDNN were $0.5(95 \%$ CI, 0.2 to 0.7$),-0.8(95 \% \mathrm{CI},-1.5$ to -0.2$)$, and $-0.7(95 \%$ CI, -1.1 to -0.2$)$. The associations were essentially unchanged when we excluded the participants $(n=556)$ whose ECGs were measured in the afternoon. The social support score was inversely associated with HR, but nonsignificantly associated with RMSSD and SDNN. There was no association of trait anger or trait anxiety with HR, RMSSD, or SDNN. The association of depression score with HR, RMSSD, and SDNN 
TABLE 1. Means (SD) of Heart Rate and Geometric Means (Inter-Quartile Range) of RMSSD and SDNN According to Gender, Race/Ethnicity, and Age, MESA

\begin{tabular}{|c|c|c|c|c|}
\hline Characteristics & $n$ & Heart Rate & RMSSD & SDNN \\
\hline \multicolumn{5}{|l|}{ Gender } \\
\hline Women & 3528 & $64.2(9.3)$ & $22.0(14.0-34.0)$ & $19.2(12.6-28.5)$ \\
\hline Men & 3124 & $61.9(9.8)$ & $20.0(13.0-31.0)$ & $18.4(12.4-27.0)$ \\
\hline Age-ethnicity adjusted overall $p$ & & $<.001$ & $<.001$ & .02 \\
\hline \multicolumn{5}{|l|}{ Race/ethnicity } \\
\hline White & 2550 & $63.0(9.5)$ & $19.6(13.0-30.0)$ & $18.6(12.6-27.2)$ \\
\hline African-American & 1843 & $63.1(10.2)$ & $25.3(16.0-39.0)$ & $21.6(14.3-32.6)$ \\
\hline Hispanic & 1472 & $63.4(9.5)$ & $20.1(13.0-31.0)$ & $17.6(11.8-26.4)$ \\
\hline Chinese & 787 & $63.1(8.7)$ & $18.6(12.0-26.0)$ & $16.4(11.4-23.6)$ \\
\hline Age-gender adjusted overall $p$ & & .55 & $<.001$ & $<.001$ \\
\hline \multicolumn{5}{|l|}{ Age (years) } \\
\hline $44-49$ & 865 & $63.5(9.1)$ & $26.0(18.0-38.0)$ & $23.7(16.3-33.2)$ \\
\hline $50-59$ & 1989 & $63.1(9.4)$ & $22.5(15.0-34.0)$ & $20.5(14.3-29.4)$ \\
\hline $60-69$ & 2025 & $63.2(9.6)$ & $19.7(13.0-29.0)$ & $17.6(11.8-25.7)$ \\
\hline 70- & 1773 & $62.8(10.0)$ & $18.7(11.0-29.0)$ & $16.2(10.5-24.8)$ \\
\hline Gender-ethnicity adjusted overall $p$ & & .35 & $<.001$ & $<.001$ \\
\hline
\end{tabular}

RMSSD = root mean square of successive differences in normal-to-normal interbeat intervals; SDNN = standard deviation of normal-to-normal interbeat intervals; MESA = Multi-Ethnic Study of Atherosclerosis.

TABLE 2. Age, Gender, Race/Ethnicity-Adjusted Means (SE) of Heart Rate, RMSSD, and SDNN According to Cardiovascular Risk Factors, MESA

\begin{tabular}{|c|c|c|c|c|}
\hline Characteristics & $n$ & $\begin{array}{l}\text { Heart } \\
\text { Rate }\end{array}$ & $\mathrm{RMSSD}^{b}$ & $\mathrm{SDNN}^{b}$ \\
\hline \multicolumn{5}{|l|}{ Hypertension ${ }^{a}$} \\
\hline Yes & 2990 & $63.5(0.2)$ & $20.3(0.1)$ & $18.0(0.1)$ \\
\hline No & 3662 & $62.8(0.2)$ & $21.3(0.1)$ & $19.2(0.1)$ \\
\hline$p$ & & .008 & .01 & $<.001$ \\
\hline \multicolumn{5}{|l|}{$\begin{array}{c}\text { Antihypertensive } \\
\text { medication }\end{array}$} \\
\hline Yes & 2207 & $63.3(0.2)$ & $19.9(0.1)$ & $18.0(0.1)$ \\
\hline No & 4445 & $63.0(0.1)$ & $21.3(0.1)$ & $19.2(0.1)$ \\
\hline$p$ & & .21 & .01 & $<.001$ \\
\hline \multicolumn{5}{|l|}{ Total cholesterol } \\
\hline$>220 \mathrm{mg} / \mathrm{dl}$ & 1437 & $63.6(0.3)$ & $19.9(0.1)$ & $18.1(0.1)$ \\
\hline$<220 \mathrm{mg} / \mathrm{dl}$ & 5193 & $63.0(0.1)$ & $21.3(0.1)$ & $19.0(0.1)$ \\
\hline$p$ & & .03 & .001 & .007 \\
\hline \multicolumn{5}{|l|}{$\begin{array}{l}\text { Diabetes } \\
\text { mellitus }\end{array}$} \\
\hline Yes & 947 & $67.3(0.3)$ & $17.4(0.1)$ & $15.7(0.1)$ \\
\hline No & 5682 & $62.4(0.1)$ & $21.7(0.1)$ & $19.4(0.1)$ \\
\hline$p$ & & $<.001$ & $<.001$ & $<.001$ \\
\hline \multicolumn{5}{|l|}{ Smoking } \\
\hline Current & 865 & $63.6(0.3)$ & $21.8(0.2)$ & $19.1(0.1)$ \\
\hline Never, former & 5787 & $63.1(0.1)$ & $20.9(0.1)$ & $18.8(0.1)$ \\
\hline$p$ & & .16 & .09 & .52 \\
\hline \multicolumn{5}{|l|}{$\begin{array}{l}\text { Body mass } \\
\text { index }\end{array}$} \\
\hline$\geqslant 30 \mathrm{~kg} / \mathrm{m}^{2}$ & 2144 & $64.9(0.2)$ & $20.7(1.0)$ & $18.5(1.0)$ \\
\hline$<30 \mathrm{~kg} / \mathrm{m}^{2}$ & 4508 & $62.3(0.1)$ & $21.1(1.0)$ & $19.0(1.0)$ \\
\hline$p$ & & $<.001$ & .28 & .14 \\
\hline
\end{tabular}

RMSSD $=$ root mean square of successive differences in normal-to-normal interbeat intervals; SDNN = standard deviation of normal-to-normal interbeat intervals; MESA = Multi-Ethnic Study of Atherosclerosis.

${ }^{a}$ Systolic blood pressure $>140 \mathrm{~mm} \mathrm{Hg}$, diastolic blood pressure $>90$ $\mathrm{mm} \mathrm{Hg}$, and/or use of antihypertensive medication.

${ }^{b}$ Geometric means. remained after adjusting for additional covariates: systolic BP, use of antihypertensive medication, smoking status, BMI, diabetes mellitus, total cholesterol level, and physical activities. When we further adjusted for use of antidepressant medications $(n=$ 424), the results were unchanged. In supplemental analyses in which we reincluded persons taking $\beta$ blockers and adjusted for their use, the association between depression and HR was unchanged, but the association between depression and HR variability was slightly weakened.

As compared with nondepressed participants $(0 \leq$ CES$\mathrm{D}<16)$, depressed participants (CES-D $\geq 16, n=686)$ had a higher mean HR value and lower mean values of RMSSD and SDNN. Age-, gender-, and race/ethnicity-adjusted mean values for nondepressed and depressed participants were 63.4 versus 64.1 for HR $(p=.049), 21.1$ versus 19.4 for RMSSD $(p=.002)$, and 19.0 versus 17.6 for $\operatorname{SDNN}(p=.002)$, respectively.

Table 4 presents multivariate-adjusted standardized regression coefficients for the association between depression and HR, RMSSD, and SDNN, stratified by gender and race/ethnicity. Depression score was similarly associated with HR in both men and women. Associations of depression with RMSSD and SDNN seemed stronger and were only statistically significant in women, but tests for heterogeneity of effects by gender were not statistically significant $(p>.50)$.

A positive association between depression and HR was only statistically significant in Whites, although there was no statistical evidence that associations of depression with HR varied by race/ethnicity ( $p$ for heterogeneity of effects by race/ethnicity >.25). An inverse association of depression with HR variability was observed in African-Americans, which was the only group in which associations were statistically significant. Further, in Whites and African-Americans, mean RMSSD and SDNN values were lower in depressed $(\mathrm{CESD} \geqslant 16)$ than in nondepressed individuals $(\mathrm{CESD}<16)$. 
TABLE 3. Associations of Psychosocial Variables With Heart Rate and Its Variability: Age, Gender, and Race/Ethnicity-Adjusted Standardized Regression Coefficients and 95\% Confidence Intervals, MESA

\begin{tabular}{lccr}
\hline Characteristics & Heart Rate & RMSSD & SDNN \\
\hline Depression & $0.5(0.2,0.7)^{\star * *}$ & $-0.8(-1.5,-0.2)^{\star *}$ & $-0.7(-1.1,-0.2)^{\star * *}$ \\
Social support & $-0.2(-0.5,-0.0)^{\star}$ & $0.5(-0.1,1.1)$ & $0.4(-0.1,0.8)$ \\
Trait anger & $0.2(-0.0,0.5)$ & $0.2(-0.5,0.8)$ & $0.0(-0.5,0.5)$ \\
Trait anxiety & $0.2(-0.1,0.5)$ & $-0.4(-1.1,0.3)$ & $-0.3(-0.8,0.2)$ \\
\hline
\end{tabular}

Standardized regression coefficients for heart rate, RMSSD, or SDNN per 1-SD increment of psychosocial variables.

MESA = Multi-Ethnic Study of Atherosclerosis; RMSSD = root mean square of successive differences in normal-to-normal interbeat intervals; SDNN = standard deviation of normal-to-normal interbeat intervals.

$* p<.05 ; * * p<.01 ; * * * p<.001$.

TABLE 4. Associations of Depression With Heart Rate and Its Variability: Multivariate-Adjusted $\dagger$ Standardized Regression Coefficients and 95\% Confidence Intervals, Stratified by Gender and Race/Ethnicity, MESA

\begin{tabular}{llll}
\hline Characteristics & Heart Rate & RMSSD & SDNN \\
\hline $\begin{array}{l}\text { Gender } \\
\text { Women }\end{array}$ & $0.4(0.1,0.7)^{*}$ & $-1.1(-2.0,-0.3)^{\star *}$ & $-0.9(-1.5,-0.2)^{\star *}$ \\
Men & $0.5(0.1,1.0)^{*}$ & $-0.6(-1.8,0.5)$ & $-0.5(-1.3,0.3)$ \\
Race/ethnicity & & & $-0.7(-1.6,0.1)$ \\
White & $0.5(0.1,1.0)^{*}$ & $-0.8(-1.9,0.4)$ & $-1.2(-2.4,-0.1)^{*}$ \\
African-American & $0.3(-0.3,0.9)$ & $-1.6(-3.2,-0.1)^{*}$ & $-0.6(-1.5,0.2)$ \\
Hispanic & $0.3(-0.1,0.8)$ & $-0.9(-2.0,0.3)$ & $0.4(-0.8,1.6)$ \\
Chinese & $0.3(-0.5,1.1)$ & $-0.1(-1.5,1.5)$ & 0.5 \\
\hline
\end{tabular}

Standardized regression coefficients for heart rate, RMSSD, or SDNN per 1-SD increment of depression.

$\dagger$ Adjusted for age, gender or race/ethnicity, systolic blood pressure, use of antihypertensive medication, smoking status, body mass index, diabetes mellitus, total cholesterol level, and physical activity. Standardized regression coefficient in heart rate, RMSSD, or SDNN per one SD (8 points) increment of depression. MESA = Multi-Ethnic Study of Atherosclerosis; RMSSD = root mean square of successive differences in normal-to-normal interbeat intervals; SDNN = standard deviation of normal-to-normal interbeat intervals.

$* p<.05 ; * * p<.01$.

Multivariate-adjusted mean values of SDNN for nondepressed and depressed participants were 19.0 versus 16.9 for Whites $(p=.005), 21.8$ versus 19.5 for African-Americans ( $p=.03$ ), 17.6 versus 17.0 for Hispanics $(p=.46)$, and 16.4 versus 16.6 for Chinese $(p=.88)$, respectively, and those of RMSSD showed a similar pattern (data not shown). Differences in the associations of depression with HR variability by race/ethnicity were marginally statistically significant ( $p$ for interaction $=.06$ for RMSSD and .03 for SDNN).

\section{DISCUSSION}

The main findings of the present cross-sectional study were that, in the full sample, depression scores measured by CES-D were positively associated with HR and inversely associated with short-term RMSSD and SDNN. This pattern was generally consistent in men and women, although associations with HR variability seemed slightly stronger in women. Although an association of depression with incidence of cardiovascular diseases is well established, the mechanisms underlying this association remain unclear. Our findings are consistent with the hypothesis that depression may be associated with incidence of cardiovascular diseases through dysregulation of the autonomic nervous system.

Although several studies have reported that depressed patients have higher HRs and/or lower HR variability compared with nondepressed persons $(6-8,28)$, only a few studies have been conducted in healthy samples $(5,9)$. Because depressive symptoms within the normal range have been associated with increased incidence of cardiovascular diseases in general populations $(1,16)$, data are needed on the associations of depression with HR and its variability in population-based samples. A previous study conducted in 2627 postmenopausal women, aged 50 to 83 years, also reported that depressive symptoms were positively associated with HR and inversely associated with SDNN measured by 24-hour monitoring (9). Another study conducted among 249 healthy women, aged 31 to 65 years, showed that depressive symptoms were not associated with 24-hour SDNN, but the small sample size of this study may have left it underpowered (5). Our results provided further evidence that depression scores are positively associated with HR in men and women and in four different race/ethnic groups. Previous prospective studies have reported that increased HR predicted increased future cardiovascular morbidity and mortality regardless gender or ethnicity (29-31). Therefore, depressive symptoms may be causally related to cardiovascular events through their association with elevated HR.

Although in general we found that depression was associated with less short-term HR variability in most groups, there was some evidence that these associations may vary according to gender and race/ethnicity. The inverse association between 
depression scores and HR variability was stronger in women than in men, and in African-Americans than in other race/ ethnic groups. This heterogeneity was marginally significant for race/ethnicity, but not for gender. Although we have no clear explanation for these ethnic differences, mean values of RMSSD and SDNN, but not HR, varied widely by race/ ethnicity in this study. These ethnic differences in HR variability may explain, in part, the ethnic heterogeneity in the association between depression and HR variability. Hence, these findings need to be replicated in other settings before any conclusions are drawn.

Social support, anger, and anxiety were not associated with either HR or short-term HR variability, whereas these psychosocial factors, as well as depression, predicted future cardiovascular events in prospective studies $(3,4,32)$. Previous studies relating these psychological factors to HR variability have been inconsistent $(5,6,33)$. Pitzalis et al. reported that, among patients with myocardial infarction, those with depression had significantly lower SDNN and baroreflex sensitivity than those without depression, but no association was found between anxiety and SDNN (33). Horsten et al. showed that women with higher social support had higher 24-hour SDNN than those with lower social support, but there was no association between anger and HR variability (5). Therefore, other mechanisms, such as platelet aggregation (34), BP reactivity (35), and adverse lifestyle including poor diet and smoking (36), may explain previously reported associations of social support, anger, and anxiety with cardiovascular diseases.

The strength of the present study is that we analyzed the associations of psychosocial factors with HR and its variability using population-based data, including various ethnic groups, with a large number of participants. Most participants in previous studies examining the associations of psychosocial factors with HR and its variability were Whites and their numbers were small, except for one recent population-based study among postmenopausal women (9). Further, in MESA, a uniform protocol was used, including questionnaires, physical measurements, and analyses of laboratory and electrocardiographic measurements in centralized core laboratories.

A limitation of this study is that the temporal relationship of depression with elevated HR and decreased HR variability cannot be inferred due to the cross-sectional design. Nevertheless, a recent randomized, controlled trial of 134 patients with stable ischemic heart disease reported that patients receiving stress management showed improved mean depression scores and increased HR variability compared with those receiving usual care (37). This finding may support a causal relationship of depression with HR variability. In the present study, HR variability was assessed only once, by 30 seconds of beat-to-beat HR recordings, which may lead to an underestimation of the associations of psychosocial factors with HR and HR variability, because of partial capture of autonomic nervous system function. On the other hand, the reliability of short-term HR and its variability were not determined in this study. This may have led to an overestimate or underestimate of the association of psychological factors with HR and its variability. Further, short-term recorded SDNN and RMSSD could be basically measuring the same phenomenon, even though long-term recording of these indices estimates different components of HR variability. Further study is needed to confirm the associations of psychosocial factors with HR variability in multi-ethnic groups using long-term recoded ECG data. A circadian rhythm for HR and HR variability may affect the associations of HR and HR variability with depression. However, in this study, most (92\%) ECGs were assessed in the morning, and the associations of depression with HR and HR variability were unchanged when we excluded the participants whose ECGs were assessed in the afternoon. Therefore, we believe that the effects of the circadian rhythm on the observed associations of depression with HR and HR variability might be modest. Although significant positive associations of depression with $\mathrm{HR}$ and $\mathrm{HR}$ variability were observed in this study, the differences in HR and HR variability between the depressive participants and the nondepressive participants were small. Therefore, it is not clear whether or not the differences are importantly related to risk of cardiovascular disease. However, the associations of HR and HR variability with incident of cardiovascular events are dosedependent $(11,32)$, suggesting that the observed differences may be meaningful to public health. Finally, although we used well-validated questionnaires to measure psychosocial factors, the use of single assessment of psychosocial factors in this study could have resulted in misclassification of psychosocial variables biasing our results toward the null. Moreover, the measurement properties of the scales we used could differ by race and ethnicity, limiting our ability to draw firm conclusions regarding race differences in the effects observed.

In conclusion, participants who report more depressive symptoms have higher HR and lower short-term HR variability than participants who report fewer depressive symptoms, whereas there were no associations of social support, anger, or anxiety with HR or its variability. Although the associations of depression with HR variability varied somewhat according to gender and race/ethnicity, the data generally support the hypothesis that depression may be associated with increased HR and reduced HR variability, which increase the risk of cardiovascular diseases.

We thank the investigators, staff, and participants of MESA for their valuable contributions. A full list of participating MESA investigators and institutions is available at http://www.mesa-nhlbi.org.

\section{REFERENCES}

1. Wulsin LR, Singal BM. Do depressive symptoms increase the risk for the onset of coronary disease? A systematic quantitative review. Psychosom Med 2003;65:201-10.

2. Iso H, Date C, Yamamoto A, Toyoshima H, Tanabe N, Kikuchi S, Kondo T, Watanabe Y, Wada Y, Ishibashi T, Suzuki H, Koizumi A, Inaba Y, Tamakoshi A, Ohno Y. Perceived mental stress and mortality from cardiovascular disease among Japanese men and women: the Japan Collaborative Cohort Study for Evaluation of Cancer Risk Sponsored by Monbusho (JACC study). Circulation 2002;106:1229-36.

3. Williams JE, Paton CC, Siegler IC, Eigenbrodt ML, Nieto FJ, Tyroler HA. Anger proneness predicts coronary heart disease risk: prospective analysis from the Atherosclerosis Risk in Communities (ARIC) Study. Circulation 2000;101:2034-9. 
4. Lett HS, Blumenthal JA, Babyak MA, Strauman TJ, Robins C, Sherwood A. Social support and coronary heart disease: epidemiologic evidence and implications for treatment. Psychosom Med 2005;67:869-78.

5. Horsten M, Ericson M, Perski A, Wamala SP, Schenck-Gustafsson K, Orth-Gomer K. Psychosocial factors and heart rate variability in healthy women. Psychosom Med 1999;61:49-57.

6. Gorman JM, Sloan RP. Heart rate variability in depressive and anxiety disorders. Am Heart J 2000;140:77-83.

7. Carney RM, Blumenthal JA, Stein PK, Watkins L, Catellier D, Berkman LF, Czajkowski SM, O'Connor C, Stone PH, Freedland KE. Depression, heart rate variability, and acute myocardial infarction. Circulation 2001; 104:2024-8.

8. Agelink MW, Boz C, Ullrich H, Andrich J. Relationship between major depression and heart rate variability. Clinical consequences and implications for antidepressive treatment. Psychiatry Res 2002;113:139-49.

9. Kim CK, McGorray SP, Bartholomew BA, Marsh M, Dicken T, Wassertheil-Smoller S, Curb JD, Oberman A, Hsia J, Gardin J, Wong ND, Barton B, McMahon RP, Sheps DS. Depressive symptoms and heart rate variability in postmenopausal women. Arch Intern Med 2005;165: $1239-44$

10. Palatini P. Elevated heart rate as a predictor of increased cardiovascular morbidity. J Hypertens 1999;17(Suppl):S3-S10.

11. Tsuji H, Larson MG, Venditti FJ Jr, Manders ES, Evans JC, Feldman CL, Levy D. Impact of reduced heart rate variability on risk for cardiac events. The Framingham Heart Study. Circulation 1996;94:2850-5.

12. Liao D, Cai J, Rosamond WD, Barnes RW, Hutchinson RG, Whitsel EA, Rautaharju P, Heiss G. Cardiac autonomic function and incident coronary heart disease: a population-based case-cohort study. The ARIC study. Atherosclerosis Risk in Communities Study. Am J Epidemiol 1997;145: 696-706.

13. Huikuri HV, Jokinen V, Syvanne M, Nieminen MS, Airaksinen KE, Ikaheimo MJ, Koistinen JM, Kauma H, Kesaniemi AY, Majahalme S, Niemela KO, Frick MH. Heart rate variability and progression of coronary atherosclerosis. Arterioscler Thromb Vasc Biol 1999;19:1979-85.

14. Carney RM, Freedland KE, Stein PK, Skala JA, Hoffman P, Jaffe AS Change in heart rate and heart rate variability during treatment for depression in patients with coronary heart disease. Psychosom Med 2000;62:639-47.

15. Carney RM, Howells WB, Blumenthal JA, Freedland KE, Stein PK, Berkman LF, Watkins LL, Czajkowski SM, Steinmeyer B, Hayano J, Domitrovich PP, Burg MM, Jaffe AS. Heart rate turbulence, depression, and survival after acute myocardial infarction. Psychosom Med 2007;69: 4-9.

16. Ohira T, Iso H, Satoh S, Sankai T, Tanigawa T, Ogawa Y, Imano H, Sato S, Kitamura A, Shimamoto T. Prospective study of depressive symptoms and risk of stroke among Japanese. Stroke 2001;32:903-8.

17. Liao D, Barnes RW, Chambless LE, Simpson RJ Jr, Sorlie P, Heiss G Age, race, and sex differences in autonomic cardiac function measured by spectral analysis of heart rate variability - the ARIC study. Atherosclerosis Risk in Communities. Am J Cardiol 1995;76:906-12.

18. Yan LL, Liu K, Matthews KA, Daviglus ML, Ferguson TF, Kiefe CI Psychosocial factors and risk of hypertension: the Coronary Artery Risk Development in Young Adults (CARDIA) Study. JAMA 2003;290: $2138-48$.

19. Bild DE, Bluemke DA, Burke GL, Detrano R, Diez Roux AV, Folsom AR, Greenland P, Jacob DR Jr, Kronmal R, Liu K, Nelson JC, O’Leary D, Saad MF, Shea S, Szklo M, Tracy RP. Multi-Ethnic Study of Atherosclerosis: objectives and design. Am J Epidemiol 2002;156: $871-81$.
20. Spielberger C. Preliminary Manual for the State-Trait Personality Inventory. Palo Alto, CA: Consulting Psychologist Press; 1980.

21. Radloff L. The CES-D scale: a self-report depression scale for research in the general population. Appl Psychol Meas 1977;1:385-401.

22. Blumenthal JA, Burg MM, Barefoot J, Williams RB, Haney T, Zimer G. Social support, type A behavior and coronary artery disease. Psychosom Med 1987;49:331-40.

23. Irwin ML, Mayer-Davis EJ, Addy CL, Pate RR, Durstine JL, Stolarczyk LM, Ainsworth BE. Moderate-intensity physical activity and fasting insulin levels in women: the Cross-Cultural Activity Participation Study. Diabetes Care 2000;23:449-54.

24. Rautaharju PM, Park LP, Chaitman BR, Rautaharju F, Zhang ZM. The Novacode criteria for classification of ECG abnormalities and their clinically significant progression and regression. J Electrocardiol 1998; 31:157-87.

25. Prineas RJ, Crow R, Blackburn H. The Minnesota Code Manual of Electrocardiographic Findings. Littleton, MA: John Wright-PSG; 1982.

26. Schroeder EB, Whitsel EA, Evans GW, Prineas RJ, Chambless LE, Heiss G. Repeatability of heart rate variability measures. J Electrocardiol 2004; 37:163-72.

27. Berkman LF, Berkman CS, Kasl S, Freeman DH Jr, Leo L, Ostfeld AM, Cornoni-Huntley J, Brody JA. Depressive symptoms in relation to physical health and functioning in the elderly. Am J Epidemiol 1986;124: 372-88.

28. Carney RM, Freedland KE, Veith RC. Depression, the autonomic nervous system, and coronary heart disease. Psychosom Med 2005;67: S29-33.

29. Gillum RF, Makuc DM, Feldman JJ. Pulse rate, coronary heart disease, and death: the NHANES I epidemiologic follow-up study. Am Heart J 1991;121:172-7.

30. Palatini P, Casiglia E, Julius S, Pessina AC. High heart rate: a risk factor for cardiovascular death in elderly men. Arch Intern Med 1999;159: 585-92.

31. Okamura T, Hayakawa T, Kadowaki T, Kita Y, Okayama A, Elliott P, Ueshima H. Resting heart rate and cause-specific death in a 16.5-year cohort study of the Japanese general population. Am Heart J 2004;147: $1024-32$.

32. Kawachi I, Sparrow D, Vokonas PS, Weiss ST. Symptoms of anxiety and risk of coronary heart disease. The Normative Aging Study. Circulation 1994;90:2225-9.

33. Pitzalis MV, Iacoviello M, Todarello O, Fioretti A, Guida P, Massari F, Mastropasqua F, Russo GD, Rizzon P. Depression but not anxiety influences the autonomic control of heart rate after myocardial infarction. Am Heart J 2001;141:765-71.

34. Wenneberg SR, Schneider RH, Walton KG, MacLean CR, Levitsky DK, Mandarino JV, Waziri R, Wallace RK. Anger expression correlates with platelet aggregation. Behav Med 1997;22:174-7.

35. Finney ML, Stoney CM, Engebretson TO. Hostility and anger expression in African American and European American men is associated with cardiovascular and lipid reactivity. Psychophysiology 2002;39:340-9.

36. Cohen S. Psychosocial models of the role of social support in the etiology of physical disease. Health Psychol 1988;7:269-97.

37. Blumenthal JA, Sherwood A, Babyak MA, Watkins LL, Waugh R, Georgiades A, Bacon SL, Hayano J, Coleman RE, Hinderliter A. Effects of exercise and stress management training on markers of cardiovascular risk in patients with ischemic heart disease: a randomized controlled trial. JAMA 2005;293:1626-34 